\title{
Erratum to: High doses of dextromethorphan, an NMDA antagonist, produce effects similar to classic hallucinogens
}

\author{
Chad J. Reissig • Lawrence P. Carter • \\ Matthew W. Johnson • Miriam Z. Mintzer • \\ Margaret A. Klinedinst • Roland R. Griffiths
}

Published online: 19 June 2013

(C) Springer-Verlag Berlin Heidelberg 2013

Erratum to: Psychopharmacology

DOI 10.1007/s00213-012-2680-6

Unfortunately, in the original publication of this article, the dose formulation was reported incorrectly. The section on Drugs in the "Materials and Methods" section should read as follows:

\section{Drugs}

Drugs and placebo were orally administered in size 0 aquacolored opaque capsules with approximately $200 \mathrm{ml}$ of water. Four identical capsules were administered in each drug session containing lactose monohydrate (Ruger Chemical Company, Linden, NJ, USA) and appropriate quantities of powdered dextromethorphan (Spectrum Chemical, Gardena, CA, USA) or triazolam tablets (Halcion; The Upjohn Company, Kalamazoo, MI, USA). Doses of dextromethorphan are expressed as the base.

The online version of the original article can be found at http://dx.doi.org/ 10.1007/s00213-012-2680-6.

C. J. Reissig • M. W. Johnson • M. Z. Mintzer • M. A. Klinedinst • R. R. Griffiths $(\square)$

Department of Psychiatry and Behavioral Sciences, Johns Hopkins University School of Medicine, 5510 Nathan Shock Drive,

Baltimore, MD 21224-6823, USA

e-mail: rgriff@jhmi.edu

R. R. Griffiths

Department of Neuroscience, Johns Hopkins University School of Medicine, 5510 Nathan Shock Drive, Baltimore, MD 21224-6823, USA

L. P. Carter

Department of Pharmacology and Toxicology, University of

Arkansas for Medical Sciences, Little Rock, AR 72205, USA 